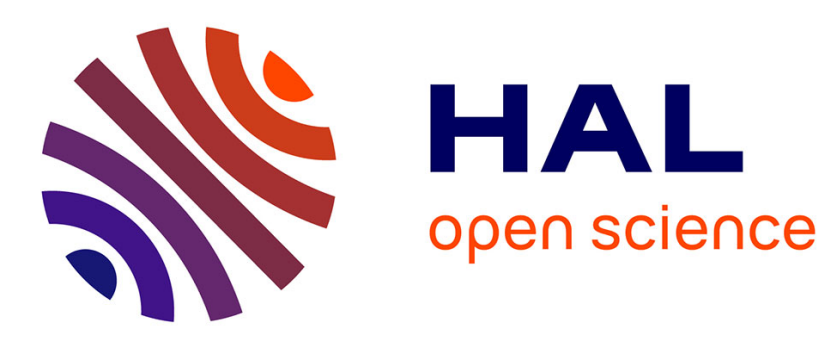

\title{
Liquid Metal Embrittlement
}

Thierry Auger, Jean-Bernard Vogt, Ingrid Proriol Serre

\section{To cite this version:}

Thierry Auger, Jean-Bernard Vogt, Ingrid Proriol Serre. Liquid Metal Embrittlement. Christine Blanc; Isabelle Aubert. Mechanics - Microstructure - Corrosion Coupling. Concepts, Experiments, Modeling and Cases, Elsevier, pp.507-534, 2019, 978-1-78548-309-7. 10.1016/b978-1-78548-3097.50022-3 . hal-03035880

\section{HAL Id: hal-03035880 https://hal.science/hal-03035880}

Submitted on 4 Mar 2021

HAL is a multi-disciplinary open access archive for the deposit and dissemination of scientific research documents, whether they are published or not. The documents may come from teaching and research institutions in France or abroad, or from public or private research centers.
L'archive ouverte pluridisciplinaire HAL, est destinée au dépôt et à la diffusion de documents scientifiques de niveau recherche, publiés ou non, émanant des établissements d'enseignement et de recherche français ou étrangers, des laboratoires publics ou privés. 


\section{Thierry AUGER, Jean-Bernard VOGT, Ingrid PRORIOL SERRE}

\subsection{Liquid metal embrittlement}

\subsubsection{Introduction}

If the terminology "hydrogen embrittlement" (HE) very explicitly points to the species responsible for the physical phenomenon, it is not the same for liquid metal embrittlement (LME). Whilst the first case suggests focusing on the presence of $\mathrm{H}^{+}$, $\mathrm{H}$ or $\mathrm{H}_{2}$, the second suggests that a priori all metals, provided that they are liquid, could lead to ductility loss. However, in terms of the literature, the number of articles dedicated to LME is much more modest than that dedicated to $\mathrm{HE}$ and accordingly the phenomena and the cases of LME are certainly less well known than those of HE.

Before giving the definition and the fundamental properties of LME, we begin by showing some examples of LME. For this phenomenon where the metal is liquid, the temperature range where this phenomenon is likely to occur is very large. Liquid metal embrittlement is likely to happen from ambient temperature or close to ambient temperature for metals with a low melting point (mercury, gallium) up to much higher temperatures but still compatible with the use of structural materials. The following case studies will allow us to highlight some characteristics of LME.

\subsubsection{Rupture of a natural gas production unit heat exchanger [COA 06]}

After the rupture of a cold box collector, an explosion and fire started in a liquid natural gas (LNG) production unit. More precisely, it was the rupture of the 
aluminum 5083-0 injection nozzle, which was used in the refrigeration of the LNG recovery plant (Figure 22.1).
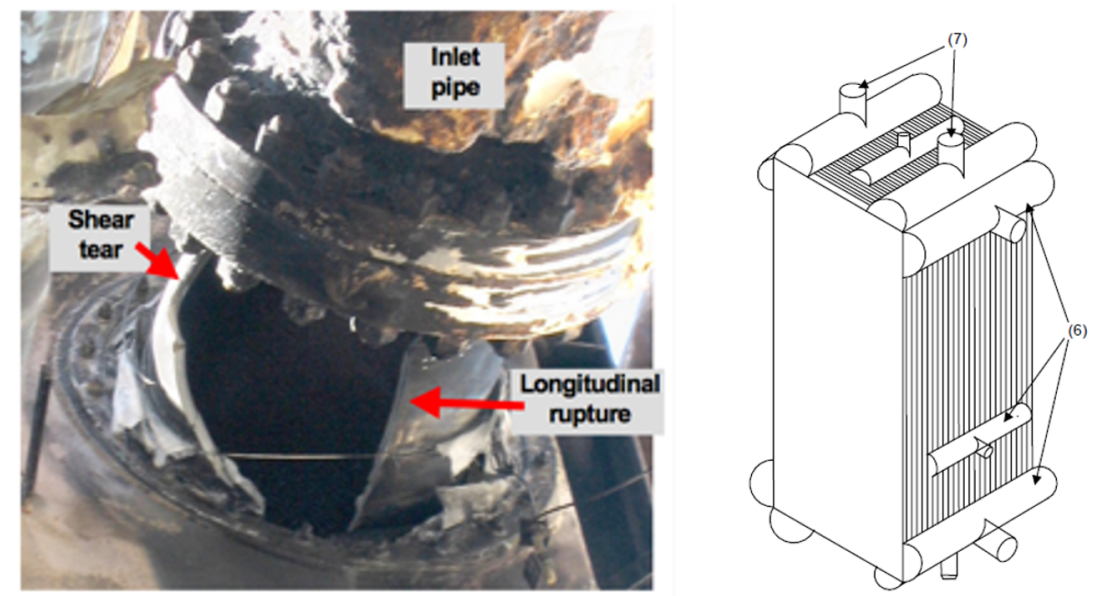

Figure 22.1. Photo of the broken injection nozzle and diagram of the heat exchanger (6: collector, 7: nozzle) [COA 06]. For a color version of this figure, see www.iste.co.uk/blanc/coupling.zip

Examination of the broken pieces showed the absence of shear lips or macroscopic signs of ductility (visible in Figure 22.1). The rupture mode was intergranular (Figure 22.2) and the fracture surface contained mercury.
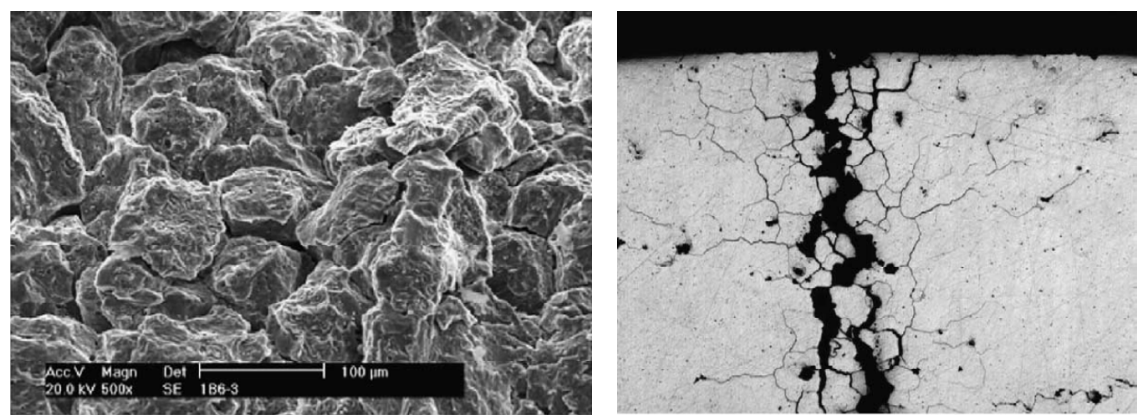

Figure 22.2. Intergranular rupture of the injection nozzle [COA 06]

The investigation concluded that the rupture of this component resulted from the presence of mercury contained in the LNG which condensed on the component's cold surfaces. Operating conditions generating localized micro-plastic deformation 
provoked the oxide layer's rupture allowing mercury to wet the aluminum alloy, thus causing very rapid propagation of any defect. The study concluded by providing some recommendations including the introduction of mercury traps to reduce or eliminate the presence of mercury and the employment of tempered aluminum alloys.

This case study is interesting because the species causing the embrittlement does not represent the majority of the products produced by the factory.

\subsubsection{Pipe rupture of a material characterization test loop in the presence of lead-bismuth [KON 06]}

The qualification of structural materials that can be used in liquid metal-cooled nuclear reactors has required the development of corrosion loops in which the materials to be studied are inserted and circulate the liquid metal. An accidental rupture of a $316 \mathrm{~L}$ steel pipe $(18 \mathrm{Cr}-2 \mathrm{Mo}-12 \mathrm{Ni})$ with a $12.7 \mathrm{~mm}$ outside diameter and $1 \mathrm{~mm}$ thickness (Figure 22.3) occurred during the temperature increase from ambient temperature to $250^{\circ} \mathrm{C}$.
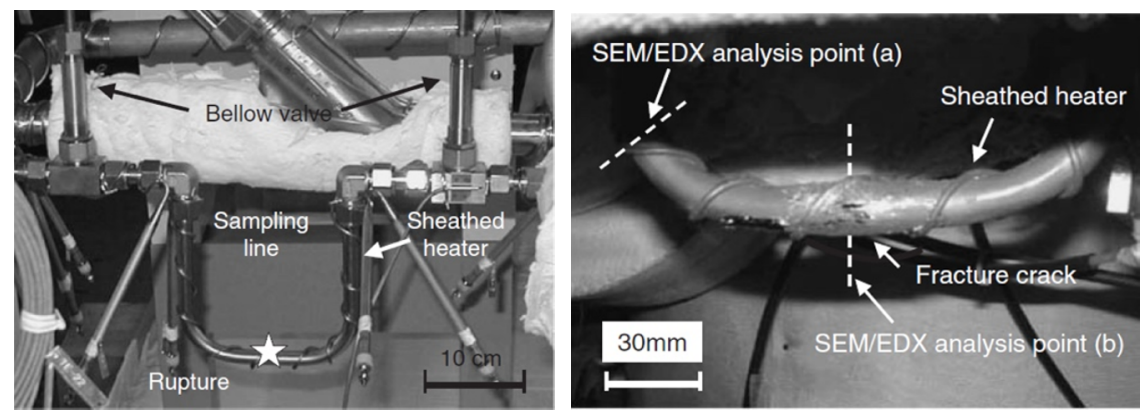

Figure 22.3. Photo of one part of the corrosion loop and the pipe [KON 06]

The crack in the pipe had a length of $8.3 \mathrm{~mm}$ and an opening of $1.1 \mathrm{~mm}$ in its middle. The pipe featured notable expansion around the crack showing the general ductile character of the material. The operating conditions were such that the pipe was in contact with the $\mathrm{Pb}-\mathrm{Bi}$ mix for $3500 \mathrm{~h}$ at $400^{\circ} \mathrm{C}$.

The analysis showed a dissolution of chromium and nickel from the surface of the pipe into the $\mathrm{Pb}-\mathrm{Bi}$ mixture. The inside of the tube became porous allowing the liquid $\mathrm{Pb}-\mathrm{Bi}$ to penetrate in this zone and insert itself in the grain boundaries. 
In addition to this effect, the mechanical effect occurred, allowing rapid propagation of the crack, which happened at $250^{\circ} \mathrm{C}$.

The analysis of the fracture surface demonstrates a ductile zone with dimples on the rupture surface close to the outside of the tube and a zone without fragile dimples on the rupture surface close to the inside of the tube (Figure 22.4).

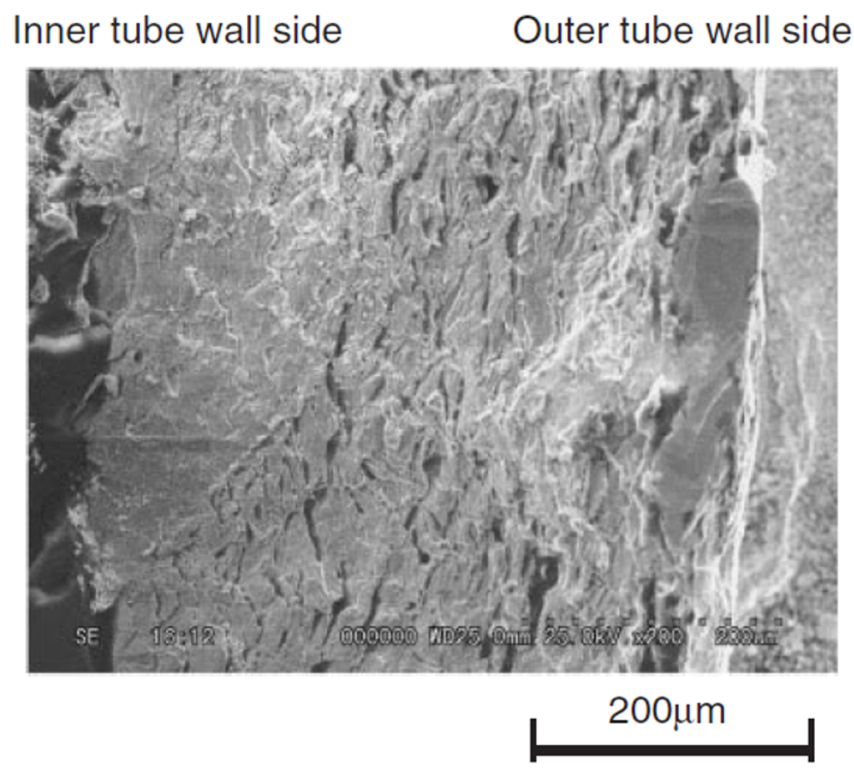

Figure 22.4. SEM image of the rupture facies [KON 06]

\subsubsection{Galvanization's effect on the microstructure and rupture of low and medium carbon steels [OKA 13]}

The last example, presented below, is related to surface treatments. It is fairly standard to overcome corrosion problems for steels by galvanization ( $\mathrm{Zn}$ ), by applying a cadmium layer (Cd) or a tin layer (Sn). Low melting point coating materials can be liquid either during the surface treatment process or during the use of a coated material if the latter is inappropriately used at high temperature.

After galvanization of an ultra-high strength steel, a wind turbine tube cracked (Figure 22.5). It should be noted that the cracking did not occur at the weld seam but in the areas where folding had been performed. 


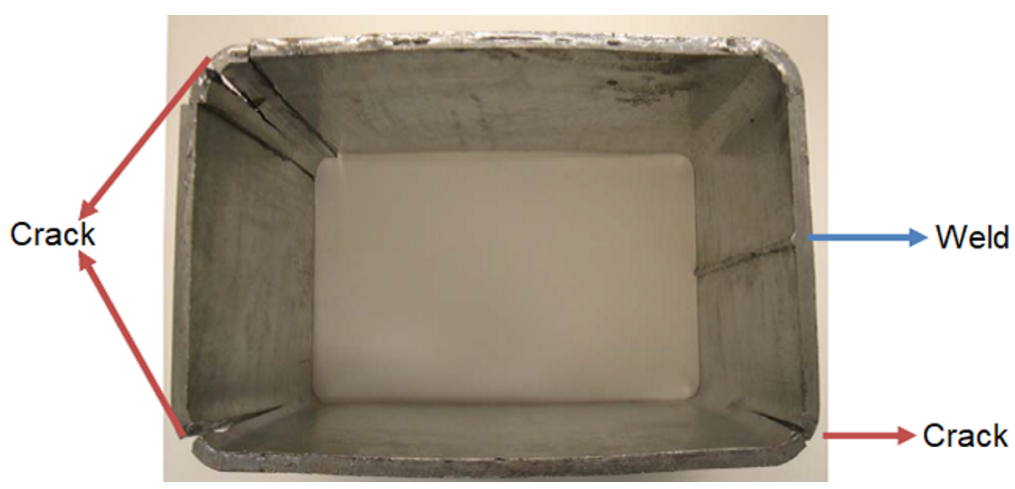

Figure 22.5. Cracking of a high strength wind turbine tube [OKA 13]. For a color version of this figure, see www.iste.co.uk/blanc/coupling.zip

The cracking of galvanized products is related to HE problems because this process uses pickling which generates hydrogen. In galvanized structures, it is proposed that hydrogen is involved in crack initiation and liquid metal in crack propagation [MRA 09]. Kinstler [KIN 05] took into account different aspects of the galvanization process and observed that lead-enriched zinc baths are more sensitive to cracking. Likewise, the addition of tin or bismuth in the galvanization bath promotes the crack growth. Finally, it was possible to remove cracking by applying a heat treatment, allowing us to decrease hardness from $300 \mathrm{HV}$ to $200 \mathrm{HV}$.

\subsection{Definition and characteristics of liquid metal embrittlement}

From these case studies, it is apparent that a metallic alloy in contact with a liquid metal may degrade.

Firstly, in the absence of mechanical loading, liquid metal corrosion can occur. It is a physical or physical-chemical process involving the dissolution of metallic alloy species in the liquid metal and their transport, chemical reactions between the elements of the metallic alloy and the liquid metal or the formation of new phases such as intermetallic compounds from the reaction of the liquid metal with the solid metal or by destabilization following the modification of the solid metallic alloy's chemical composition. For more information, the reader could refer to, for example, the report on liquid metal corrosion models written by Zhang et al. [ZHA 10] and to the chapter on the French website Techniques de l'ingénieur written by BalbaudCelerier and Martinelli from CEA-Saclay [BAL 13]. 
Then, a crack which appears to be brittle in appearance can occur in a ductile material if the latter is subject to mechanical loading in the presence of a liquid metal. This is known as liquid metal embrittlement (LME). The possibility of modifying the crack propagation mode is the most striking fact reported in the case studies. Nevertheless, crack behavior in the presence of a metal can simply be modified only by its speed. This is known as liquid metal accelerated damage.

Several questions occur repeatedly:

- Is liquid metal embrittlement quite simply a particular case of stress corrosion (SCC) and similar to HE?

- Does the liquid metal act on the initiation phase or the propagation phase?

- Is the sensitivity to embrittlement predictable?

Whilst similarities exist between LME, HE and SCC, notably in terms of the fractography and the propagation rate, notable differences exist in terms of:

- the absence of electrochemical processes in LME;

- the large variety of atoms responsible for LME;

- the size of the atoms responsible for LME;

- the diffusion of the embrittling species atoms in the solid matrix.

Thus, the notion of specificity, established in the 1960s, which lists the liquid metal-solid metal couples resulting in embrittlement (Table 22.1), was quickly abandoned because a variation in the experimental conditions can cause the appearance or disappearance of LME.

\begin{tabular}{|c|c|c|c|c|c|c|c|c|c|c|c|c|c|c|c|}
\hline \multirow[b]{2}{*}{ Solid } & \multicolumn{15}{|c|}{ Liquid } \\
\hline & $\mathrm{Hg}$ & $\mathrm{Cs}$ & $\mathrm{Ga}$ & $\mathrm{Na}$ & In & $\mathrm{Li}$ & Sn & $\mathbf{B i}$ & $\mathrm{Tl}$ & $\mathrm{Cd}$ & $\mathrm{Pb}$ & $\mathrm{Zn}$ & $\mathrm{Te}$ & $\mathrm{Sb}$ & $\mathrm{Cu}$ \\
\hline Sn & $\mathrm{X}^{*}$ & & & & & & & & & & & & & & \\
\hline $\mathrm{Bi}$ & $x$ & & & & & & & & & & & & & & \\
\hline $\mathrm{Cd}$ & $\mathrm{x}$ & $x$ & $x$ & & & & $x$ & & & & & & & & \\
\hline$Z_{n}$ & $\ddot{x}$ & & $x$ & & & & $\mathrm{x}$ & & & & $x$ & & & & \\
\hline $\mathrm{Mg}$ & & & & $x$ & & & & & & & & $x$ & & & \\
\hline $\mathrm{Al}$ & $x$ & & $x$ & $\mathrm{x}$ & $x$ & & $x$ & & & $x$ & & $x$ & & & \\
\hline $\mathrm{Ge}$ & & & $\mathrm{x}$ & & $x$ & & $x$ & $x$ & $x$ & $x$ & $x$ & & & $x$ & \\
\hline $\mathrm{Ag}$ & $\mathrm{x}$ & & $x$ & & & $x$ & & & & & & & & & \\
\hline $\mathrm{Cu}$ & $\mathrm{x}$ & & $x$ & $x$ & $x$ & $\mathrm{x}$ & $?$ & $x$ & & & $x$ & & & & \\
\hline $\mathrm{Ni}$ & $x$ & & & & & $\mathrm{x}$ & $x$ & & & & $x$ & & & & \\
\hline $\mathrm{Fe}$ & $\mathrm{X}$ & & & & $x$ & $x$ & $x$ & & & $x$ & $x$ & & $x$ & $x$ & $?$ \\
\hline $\begin{array}{l}\mathrm{Pd} \\
\mathrm{Ti}\end{array}$ & $\mathrm{x}$ & & & & & $x$ & & & & $x$ & & & & & \\
\hline
\end{tabular}

Table 22.1. Liquid metal-solid metal couples deemed sensitive to LME [FER 96] 
Furthermore, materials in service are not pure metals but very often alloys.

The case studies mentioned previously make it possible to determine the prerequisite for embrittlement:

- intimate contact between the liquid metal and the solid metal;

- plastic deformation.

And the promotive or inhibitory factors:

- metallurgical state of the solid material;

- and, therefore the mechanical resistance and toughness of the solid material;

- chemical and viscosity properties for the liquid metal;

- test temperature;

- speed of mechanical loading;

- the triaxiality of the stresses.

The following paragraph is dedicated to test methods highlighting liquid metal embrittlement and the strategy to take into account the key parameters mentioned previously.

\subsection{Highlighting liquid metal embrittlement}

\subsubsection{Specificity and general precautions for mechanical tests in the presence of liquid metal}

Classically, LME studies utilize smooth test specimens and notched test specimens to study the liquid metal's role on crack initiation and propagation respectively.

Currently, studies to understand LME are mostly conducted with regards to the nuclear field and the liquid metals considered are mercury, lead, eutectic leadbismuth, lead-lithium alloys and sodium. To document in more depth the properties of lead and eutectic $\mathrm{Pb}-\mathrm{Bi}$ and its effects on solid metallic alloys, the reader is invited to consult the book Handbook on Lead-Bismuth Eutectic Alloy and Lead Properties, Materials Compatibility, Thermal-hydraulics and Technologies [NEA 15]. 
Beyond the type of mechanical test, several elements are taken into account when defining tests and protocols:

- instrumentation;

- potential dangerousness of the medium;

- control of the liquid metal chemistry throughout the test;

- the state of the interface before and during mechanical testing.

Heavy metals may present, above all, a toxicological risk either by contact at room temperature, or by inhalation at high temperature. In the latter case, it is required to design and perform experiments in isolated work cells. Sodium has a risk of explosion and inflammation (sodium fire) upon contact with water and oxygen. These two risks require that the tests with liquid sodium are performed in an oxygen- and $\mathrm{H}_{2} \mathrm{O}$-controlled atmosphere.

Unlike an aqueous environment, liquid metals are opaque and will permit no observation of the test specimen's surface during the test. Strain measurements of the test specimen are in general indirect (displacement measurement of the testing machine's traversing beam, remote extensometer) and the installation of a displacement sensor on the useful zone of the test specimen is very rare [GON 14].

In addition to the attention given to LME mechanisms, it has been necessary to focus on the development of new instruments such as oxygen probes for liquid metals [COU 04, NEA 15]. Designed, manufactured and calibrated in laboratories, they are generally based on the principle of a galvanic cell. The analysis of the atmosphere in contact and in equilibrium with the liquid metal can permit also, under certain assumptions for the interface, the assessment of the impurity rate $(\mathrm{H}, \mathrm{O})$ in the liquid metal. Notably, in a liquid sodium environment, experimental measures of the dissolved oxygen content are very complicated and Noden's empirical law is mostly used.

Protocols and equipment have also been put in place in order to obtain, before testing, a liquid metal with a controlled chemistry (purification system) but also devices allowing monotonic and cyclic mechanical tests in liquid metal in a controlled atmosphere [BOS 07, GON 14, HAM 14, HEM 13, YE 14a, YE 15, YUR 11]. Regarding the eutectic alloy $\mathrm{Pb}-\mathrm{Bi}$ and $\mathrm{Pb}$, this involves notably decreasing the rate of oxygen dissolved from the saturation value to a lower value. This purification is performed at high temperatures (between $450^{\circ} \mathrm{C}$ and $550^{\circ} \mathrm{C}$ depending on the laboratory and assembly constraints) and under a flow of argon/hydrogen, as in Figure 22.6(a) for example [YE 14b]. In the case of liquid sodium, a zirconium strip can be placed in the liquid sodium bath, heated to 
$600-650^{\circ} \mathrm{C}$. Maintaining the temperature for several days allows one to obtain oxygen concentrations lower than $10 \mathrm{ppm}$. It turns out that the carbon content is also lowered a little but overall the sodium remains carburizing for steels. A carbon concentration of around $20 \mathrm{ppm}$ is probably reached. The concentration in hydrogen in a liquid sodium environment is not controlled; this element is not problematic for liquid sodium corrosion which is the key area driving the development of experimental protocols regarding the control the impurity of liquid metals.

Figure 22.6(b) [YUR 11] illustrates an experiment aiming to characterize the creep resistance of a steel in lead at $650^{\circ} \mathrm{C}$, demonstrating the use of the measurement probe for the liquid bath's chemistry.
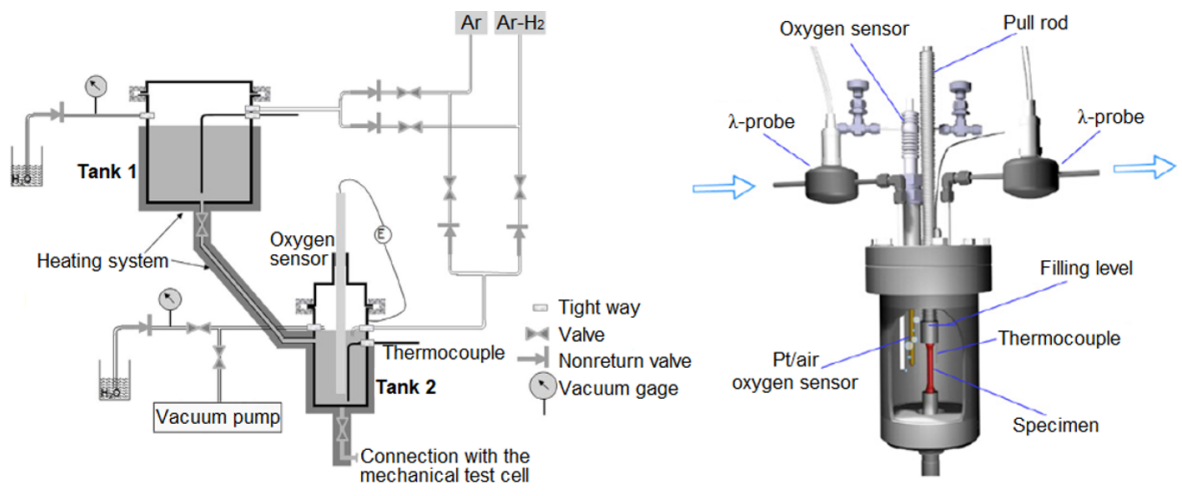

Figure 22.6. (left) purification unit for eutectic $\mathrm{Pb}-\mathrm{Bi}[\mathrm{YE}$ 14b] and (right) creep experiment in the presence of a liquid metal with control of the environment's chemistry according to [YUR 11]

\subsubsection{Importance of choosing the mechanical test when highlighting liquid metal embrittlement}

\subsubsection{Monotonic loading}

The oldest, most basic and best known way of studying LME is to employ a monotonic tensile test on a smooth specimen [AUG 05, BOS 07, DAI 06, IRF 97a, NIC 01, SKE 94, THO 94, VAN 06, WES 79, YE 04]. This test easily highlights the solid material's sensitivity to LME notably when the test specimens have a low surface/volume ratio and are exempt from any geometric defects. Indeed, as the liquid metal can act only from the test specimen's surface, it is necessary, at a minimum, that the liquid metal embrittles before the damage in the bulk of the test specimen occurs at the moment of necking where the effects of strong triaxiality is felt. Sometimes, the onset of LME is delayed up to necking. Other conventional tests 
have also been employed such as the bending test on a parallelepipedal test specimen or on saddle-shaped test specimens [BAK 14].

The use of a small punch test (SPT) [YE 14b] has proven to be much more severe because the surface/volume ratio is higher and the stress state is biaxial, at least at the start of the test. This test involves stamping a square or circular shaped sample and recording the evolution of the force according to displacement. The tensile face is in contact with the liquid metal. Thus, for a collection of identical experimental conditions (loading speed, temperature, liquid metal, etc.) employed for the tensile tests, LME can be highlighted by SPT [VOG 13] (Figure 22.7). This graph represents the mechanical response of a martensitic steel having sustained different tempering temperatures. The steel tempered at $500^{\circ} \mathrm{C}$ breaks with very little plasticity and presents brittle rupture in the presence of liquid metal.
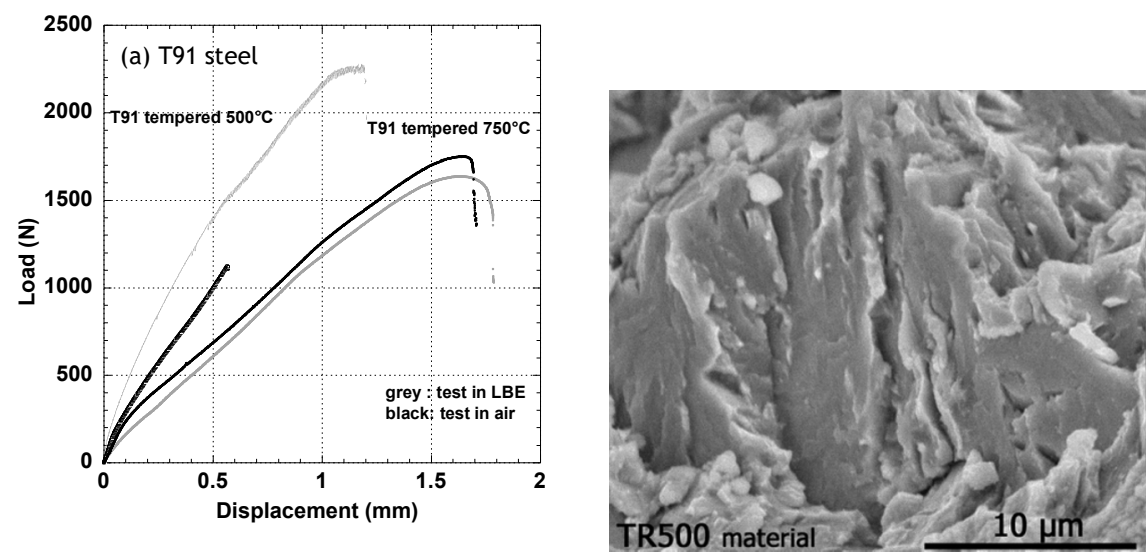

Figure 22.7. SPT curves for a martensitic steel subjected to different tempering temperatures and SEM image of the $500^{\circ} \mathrm{C}$ tempered steel according to [VOG 13]

\subsubsection{Cyclical loading}

To understand the role of cyclical loading, low-cycle fatigue tests are preferred to high-cycle fatigue tests because of the macroscopic plastic deformation present in low-cycle fatigue tests. The principle is similar to that of corrosion fatigue tests. No electrochemical measurement is however performed.

The presence of a liquid metal affects, to varying degrees depending on the solid metallic alloy, the fatigue resistance. In general, when compared to the exposure to air condition, fatigue life is reduced by the presence of eutectic Pb-Bi [VER 05, 
CAR 17, VOG 13] (Figure 22.8(a)). For liquid sodium, it is the opposite [KAN 09] (Figure 22.8(b)). The cause of the reduction or the increase in the fatigue life is however different.
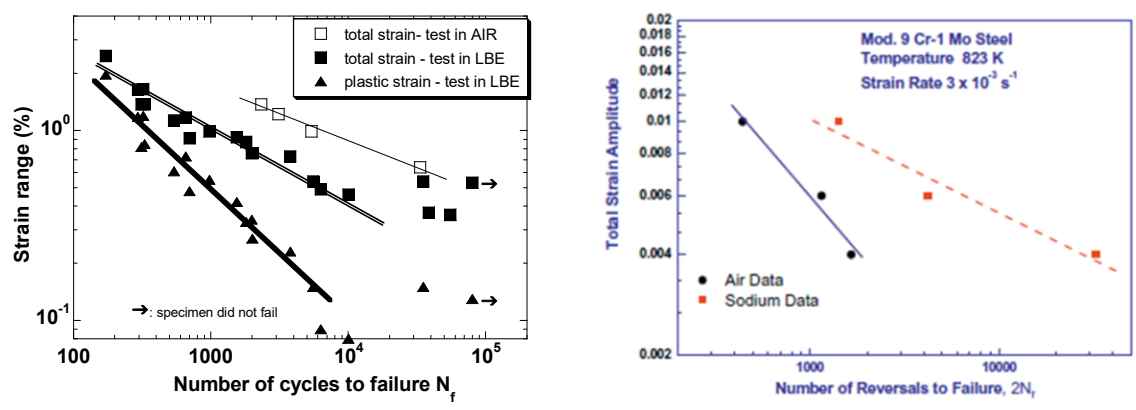

Figure 22.8. Reduction (left) and increase (right) of the fatigue life due to the presence of a liquid metal for a martensitic steel [VOG 13, KAN 09]

\subsubsection{Ductility troughs}

Liquid metal embrittlement only happens in a given range of testing parameters (temperature, strain rate), and a standard way of representing the effect is via the "ductility trough" representing the characteristic value of the desired performance (elongation at rupture, fatigue life) according to a characteristic value to be studied (temperature, strain rate, etc.) (Figure 22.9).
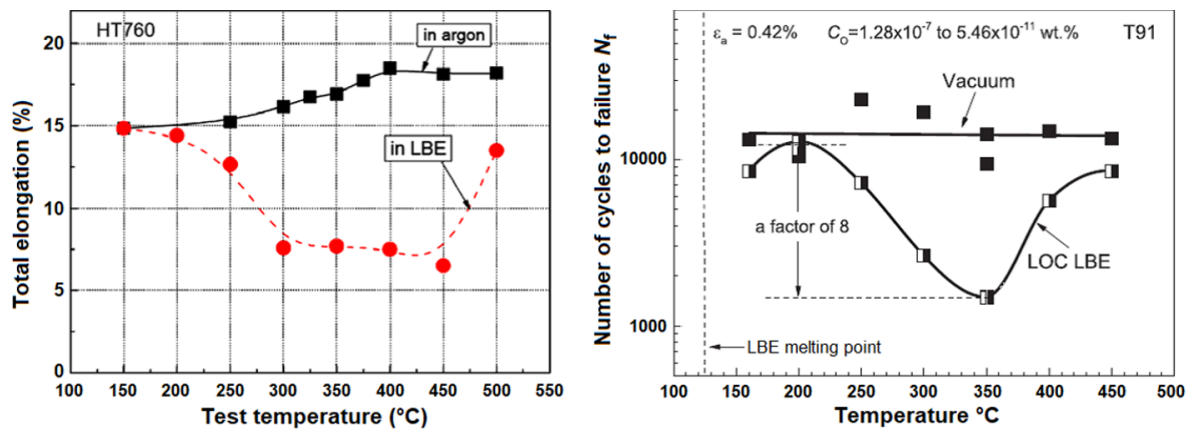

Figure 22.9. Demonstration of the ductility trough by considering the elongation at rupture (left) or the fatigue life (right) according to the test temperature according to [LON 08a] and [GON 16a] respectively. For a color version of this figure, see www.iste.co.uk/blanc/coupling.zip 


\subsubsection{Fracture mechanics test}

To characterize more quantitatively the role of liquid metals on crack propagation, two conventional tests are used: the toughness test and the fatigue crack propagation test. The use of non-standard notched test specimens to give a better understanding is also frequently met [HAA 01, HAM 11a]. A question often raised concerns pre-cracking, namely if it must be performed in liquid metal or in air. The results for toughness or measurement of fatigue propagation rates in liquid metal are very few.

For the toughness measurement, the dimensions of the test specimen were guided either to induce plane stress state or a plain strain state [AUG 11, COE 10, FEY 16, HOJ 11, LON 08b, VAN 09]. It is possible to observe drops in toughness of around $87 \%$ in plain strain when the test is performed in the presence of $\mathrm{Pb}-\mathrm{Bi}$ in place of an $\mathrm{Ar}-\mathrm{H}_{2}$ mixture (Figure 22.10) with pre-cracking in $\mathrm{Pb}-\mathrm{Bi}$. If this pre-cracking is performed in air, the effect is much less obvious (Figure 22.10).
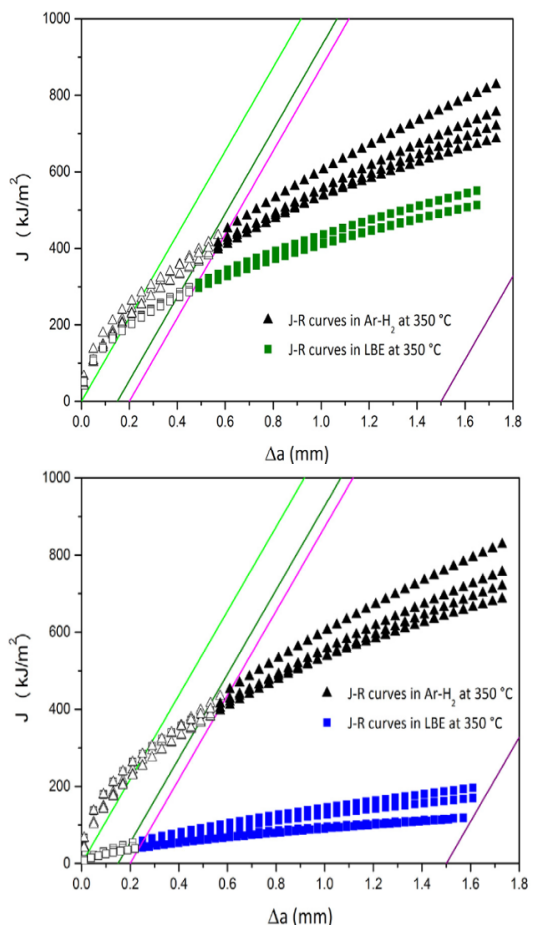

Figure 22.10. Toughness curves (plain strain) for T91 steel in an Ar-H2 environment and in the eutectic $\mathrm{Pb}-\mathrm{Bi}$ at $350^{\circ} \mathrm{C}$, with pre-cracking in air (top) and pre-cracking in $\mathrm{Pb}-\mathrm{Bi}$ (bottom) [FEY 16]. For a color version of this figure, see www.iste.co.uk/blanc/coupling.zip 
Under cyclical loading [VER 05, VOG 17] for a martensitic steel loaded in the presence of eutectic $\mathrm{Pb}-\mathrm{Bi}$ at $300^{\circ} \mathrm{C}$, the propagation rate can be 10 times greater than in air (Figure 22.11(a)). This increase in the propagation rate will accompany a change in the crack propagation mode. A ductile-streaked facies (Figure 22.11(b)) observed in the test specimen, which has been broken in air, will be replaced by trans- and intergranular fragile facies (Figure 22.11(c)).
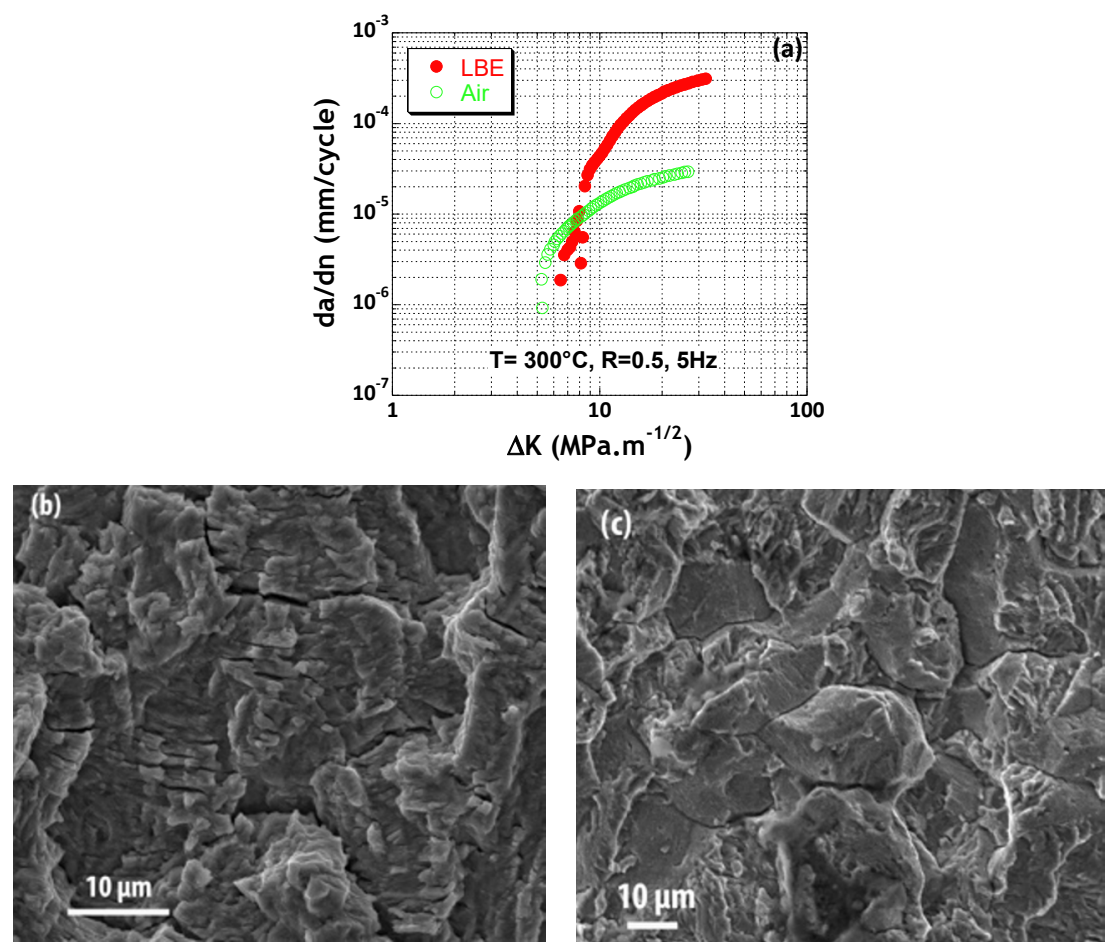

Figure 22.11. Fatigue propagation behavior in air in the presence of eutectic $\mathrm{Pb}$-Bi for a martensitic steel [VER 05, VOG 17]. For a color version of this figure, see www.iste.co.uk/blanc/coupling.zip

\subsubsection{Importance of experimental conditions for highlighting liquid metal embrittlement}

\subsubsection{Importance of the surface quality}

One of the prerequisites for observing LME is close contact between the liquid metal and the solid metal. Structural metallic materials are covered with a native oxide film which can create a barrier to contact by adsorption and thus prevent the LME starting. Furthermore, this oxidized interface evolves by corrosion in the liquid metal. 
There is therefore a significant coupling between the corrosion phenomena which can take place at the solid/liquid interface and sensitivity to LME. The initiation of premature cracking is thus very sensitive to the specific details of the experimental protocol used and the type of mechanical test. Use of pre-wetting protocols is developing and specific protocols are becoming widespread in experimental studies. Several methods are possible to allow direct contact: physical-chemical pre-stripping of the native oxide layer [AUG 04], pre-immersion in liquid metal allowing the absence of the oxide layer or the penetration of the liquid metal [GON 14, HEM 13, HAM 14], and pre-cracking in liquid metal before testing [HOJ 11, VOG 17]. These treatments must be correctly controlled in order to destroy the native film to obtain intimate contact without generating metallurgical modifications in the material. These specific conditions for each system require dedicated research linked to a good understanding of the physical-chemical properties of the liquid metal and its coupling with the material. For example, prolonged exposure to sodium can result in preferential corrosion at the grain boundaries with associated sodium penetration, conditions which are favorable to crack initiation [HAM 14]. Several cases of reactive pre-wetting have furthermore been developed recently where one can observe a wetting transition on an oxide which is formed in situ [BAR 18, HEM 14]. Thus, for example, for tests undertaken on steels in liquid sodium, an excursion towards temperatures of $450^{\circ} \mathrm{C}$ to $550^{\circ} \mathrm{C}$ during a relatively short time is undertaken in order to ensure sufficient wetting even if the tests are performed at lower temperatures.

Finally, some systems require no particular precaution for initiation like steels with a high elastic limit [LEG 00]. In this case, we can think that the continuity of the native oxide layer is broken beyond a certain deformation and no longer offers effective protection.

The key role of the liquid metal is very visible in the initiation phase. Thus the presence of defects or notches generated during machining [DAI 06] or by corrosion [VOG 13], apparently stable, in an inert environment can become a source of cracking in the presence of liquid metal. Thus it is recommended to pay close attention when the solid metallic alloy is immersed in a liquid metal, particularly those which are oxygen deprived, it being subject to selective dissolution. It can degrade the surface quality and create micro-defects which are able to propagate in the liquid environment [VOG 13].

\subsubsection{Importance of the liquid metal's chemistry}

Because intimate contact is a prerequisite for LME, oxygen control becomes very important. Indeed, a high oxygen content in the liquid metal will oxidize the liquid metal's fresh surface which acts as a barrier to LME [YE 14a, GON 16a, CAR 17] (Figure 22.12). 


\subsubsection{Strain rate importance}

Like many cases of environmentally-assisted rupture, strain rate plays an important role. Liquid metal embrittlement happens a lot more when the deformation rate is slow. Nevertheless, unlike SCC in an aqueous environment where slow deformation rate tests will sometimes accompany dissolution phenomena due to prolonged time spent in the solution, the sensitivity to the deformation rate results from the effects of plasticity and plasticity-liquid metal interaction. Deformation rate effects are sometimes coupled with the effects of the bath's chemistry (Figure 22.12).
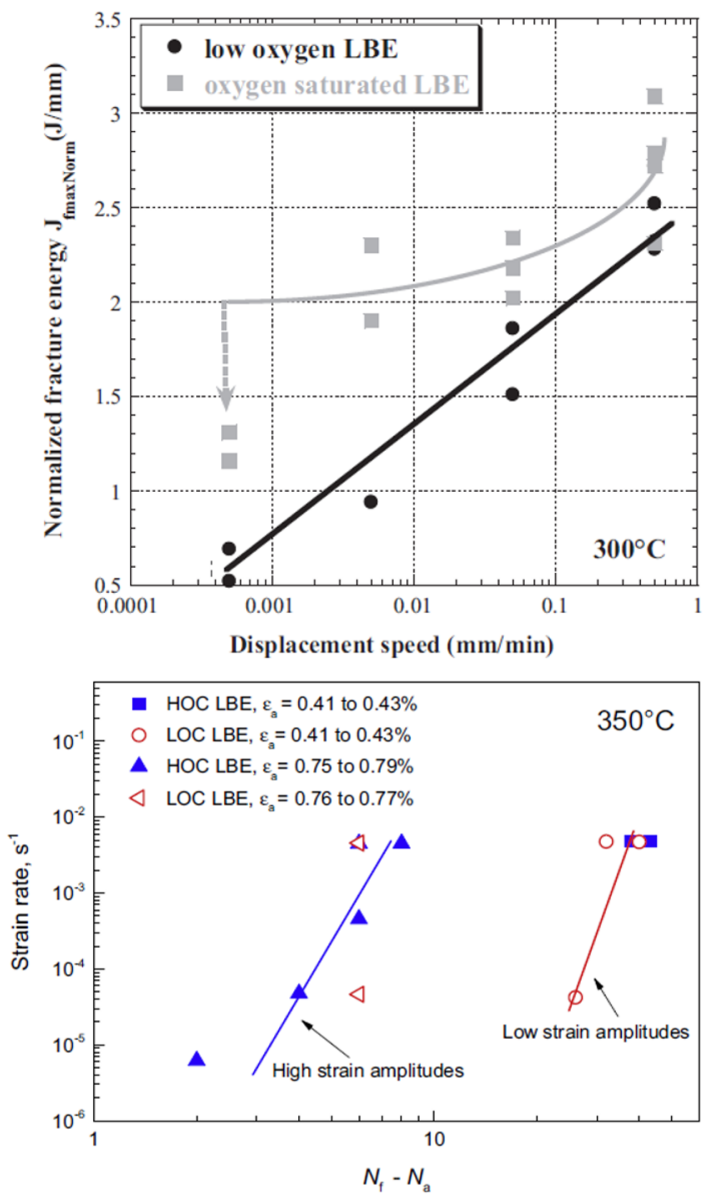

Figure 22.12. Effect of the mechanical loading speed and the oxygen content on the rupture energy measured by SPT (top) and on the number of cycles during the propagation phase in fatigue (bottom) according to [YE 14b] and [GON 16a] respectively. For a color version of this figure, see www.iste.co.uk/blanc/coupling.zip 


\subsection{Liquid metal embrittlement mechanisms}

\subsubsection{Prerequisites}

The interaction of a liquid metal with a solid metal results in a phenomenology that we can classify into two distinct categories:

- spontaneous wetting at the grain boundaries that we can observe in the emblematic case of LME such as the $\mathrm{Al} / \mathrm{Ga}$ or $\mathrm{Cu} / \mathrm{Bi}$ couple [LUD 05]. In these cases, very rapid intergranular penetration leads to complete ruin of the material with catastrophic consequences without ever undergoing mechanical loading;

- liquid metal embrittlement in the sense of a decrease in the cracking resistance during mechanical loading caused by the effect of adsorption of the liquid metal. Two sub-categories exist. The couple brass/Hg for example belongs to the first with a very rapid propagation of several $\mathrm{cm} / \mathrm{s}$ once started. Mechanical loading of the crack is then supercritical. The second sub-category groups the cases where the crack is sub-critical with regards to the mechanical loading and propagates much more slowly and thus can be controlled by the loading speed [FER 97].

We can qualitatively understand these two categories by thermodynamic analysis (via an energy assessment). Consider a solid (here containing a grain boundary) interacting with a liquid without the application of a stress field. The energy cost of the grain boundary is recorded by $\gamma_{J d G}(\Theta)$ where $\Theta$ represents the coverage rate of the grain boundaries with impurities. We can thus take into account a possible diffusion at the grain boundaries of the embrittling metal. The energy cost of the two solid-liquid interfaces is recorded by $2 \gamma_{S L}$. The wetting parameter $\mathrm{S}_{\mathrm{JdG}}$ then measures the difference in energy between the initial situation where the grain boundary was cohesive and the final situation where the grain boundary has been replaced by a liquid film. It is written as:

$$
S_{J d G}=\gamma_{J d G}(\Theta)-2 \gamma_{S L}
$$

If the energy reduction caused by the adsorption of the liquid metal is low, then the energy gain to expect $\left(\mathrm{S}_{\mathrm{JdG}}<0\right)$ is not sufficient to lead to the evolution of the system towards a state where the grain boundaries would be unstable (Figure 22.13(a)). We can then observe a slow evolution of the triple junction by surface diffusion or by volumetric diffusion, referred to as Mullins' engraving, which will be refined to satisfy Young's equation at the triple point $\left(\gamma_{\mathrm{ddG}}=2 \gamma_{\mathrm{SL}} \cos (\theta / 2)\right)$ [MUL 60]. If, however, the energy gain is expected to be positive $\left(\mathrm{S}_{\mathrm{JdG}}>0\right)$ then the evolution of the system may result in the rupture of the grain boundary and the formation of a liquid film at the joint which is more favorable energetically (Figure 22.13(b)). 

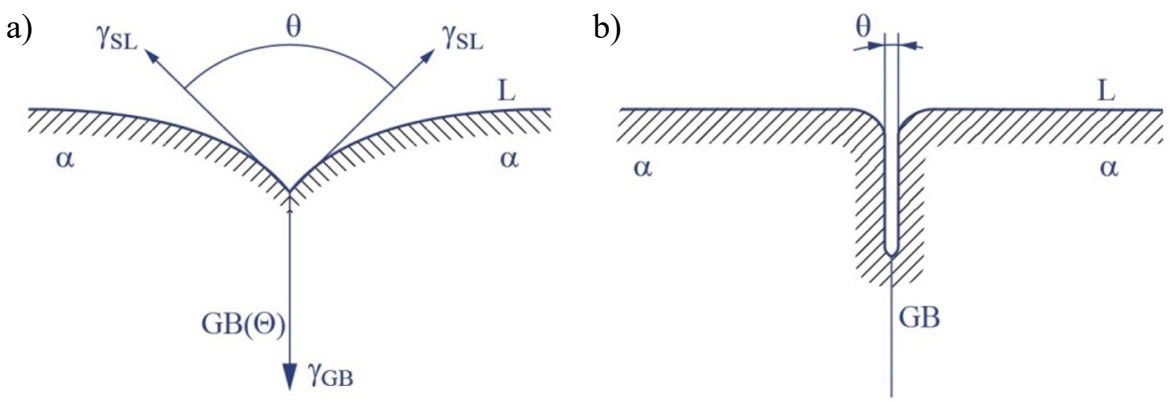

Figure 22.13. (a) $S_{J d G}<0$, the grain boundary is stable b) $S_{J d G}>0$, a liquid film at the grain boundary is favorable [EUS 99]

The evolution in temperature of these energies allows us to understand qualitatively the occurrence of spontaneous wetting at grain boundaries which occur at high temperatures in the first category. Indeed, the temperature dependence for the Gibbs energy of a grain boundary $(\Delta \mathrm{G}=\Delta \mathrm{H}-\mathrm{T} \Delta \mathrm{S})$ will always be less than that of a solid-liquid interface. The Gibbs energy of a solid-solid interface makes an entropic contribution which is principally vibrational and mostly linear with regards to temperature. A solid-liquid interface will have a chemical contribution $(\Delta \mathrm{H})$ which will stem from the evolution of the solid element's solubility in the liquid when we increase the temperature. The evolution is therefore more marked by principle. Thus, a relatively low temperature threshold can therefore exist starting from which the temperature evolution of the term $2 \gamma_{\mathrm{SL}}$ will sufficiently lower the energy of the solid-liquid interface which then makes the formation of a liquid film at the joint possible (Figure 22.14).

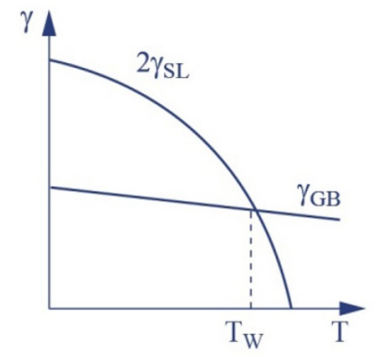

Figure 22.14. Qualitative evolution of the temperature of Gibbs energy of a grain boundary and a solid-liquid interface. $T_{W}$ is the transition temperature

The first category of LME phenomenology that is described by a low threshold temperature $\left(\mathrm{T}_{\mathrm{W}}\right)$ concerns nevertheless only a small fraction of the known cases 
$(\mathrm{Al} / \mathrm{Ga}, \mathrm{Cu} / \mathrm{Bi}, \mathrm{Fe} / \mathrm{Zn}, \mathrm{Ni} / \mathrm{Bi}$ and $\mathrm{Mo} / \mathrm{Bi}$ notably) [WOL 02 ]. Most of the other cases concern the second category (high $\mathrm{T}_{\mathrm{W}}$ ) for which this criterion which is purely energetic does not predict formation of an intergranular film. In this situation, we thus have an energy barrier for the rupture (localized here at the grain boundary). It is the role of mechanical loading to supply the supplementary energy to overcome this energy barrier.

\subsubsection{Cracking and interfacial rupture routes}

Liquid metal embrittlement is also characterized by a variety of rupture surfaces which potentially opens up several possibilities for the cracking path (intergranular, cleavage intragranular, rupture at microstructural interfaces). The determination of the cracking path is a prerequisite necessary to correctly understand what happens at the microscopic level during rupture. This also conditions the models which are required to be developed in order to have a more generic description. If the intergranular character in many model systems is not in doubt, it is not the same for many systems where the material can have a complex microstructure or a complex plastic response during mechanical loading. We can thus look at the case of rupture induced by liquid indium at $200^{\circ} \mathrm{C}$ for Armco iron. The intergranular character is irrefutable here (Figure 22.15(a)). The cases of T91 martensitic steel (Fe-9\% $\mathrm{Cr}-1 \% \mathrm{M}$ o) in contact with eutectic $\mathrm{Pb}-\mathrm{Bi}$ (Figure 22.15(b)) and cracked 304L austenitic steel in contact with liquid sodium (Figure 22.15(c)) are however not as simple because the rupture mode does not seem to have an immediate link with the material's initial microstructure. Thus what can be said about the rupture mechanism of these three systems?

a)

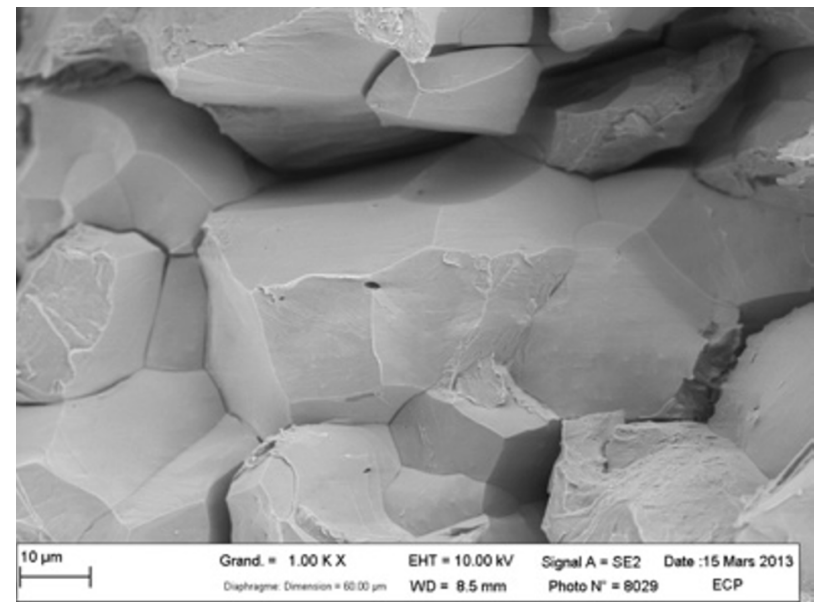


b)

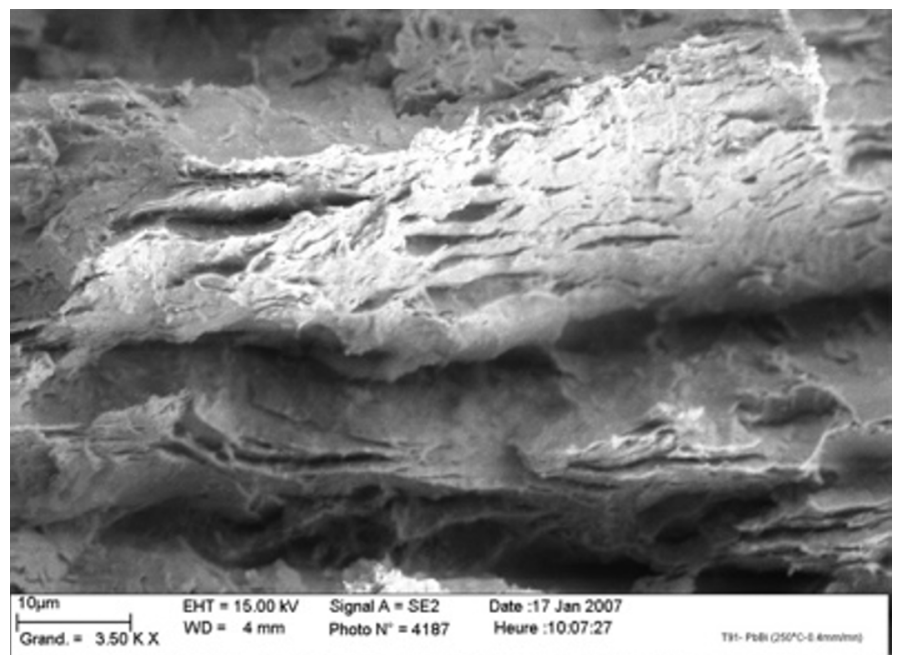

c)

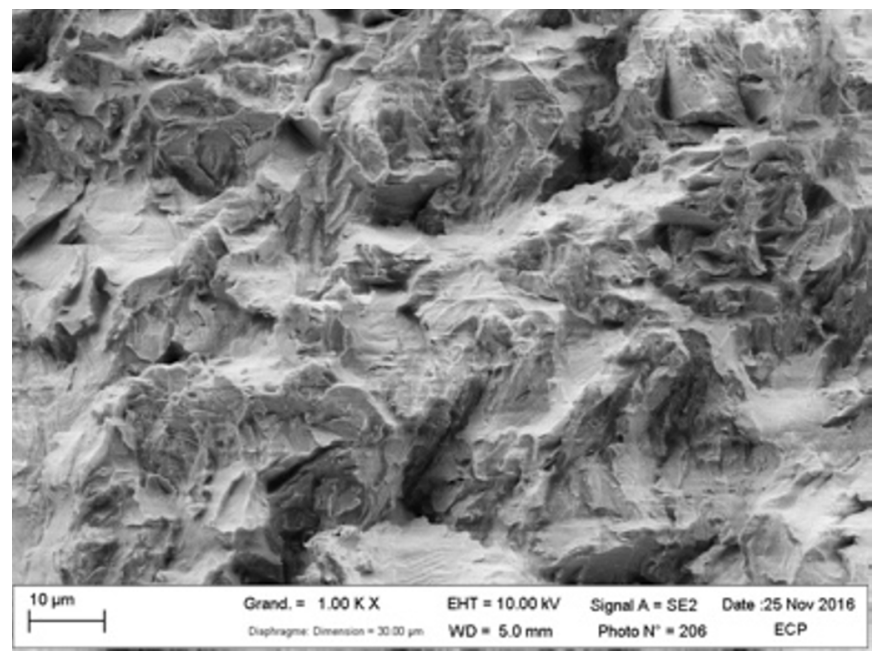

Figure 22.15. a) Rupture surface of the iron Armco/Indium system; b) rupture surface of the T91/PbBi system; c) rupture surface of the 304L/Na system

Studies have been undertaken on the rupture mode in monotone uniaxial loading [BAR 17, MAR 12]. Transmission Electron Microscopy (TEM) lamellae including stopped cracks have been machined by FIB perpendicularly to the rupture surface for these two last systems (Figure 22.16(a)). They have then been analyzed by automatic TEM indexing (ACOM-TEM [RAU 08]) in order to obtain mapping of the phases in presence and orientation with a nanometric resolution (Figure 22.16(b)). 
In the case of the $\mathrm{T} 91 / \mathrm{Pb}-\mathrm{Bi}$, these are the martensitic laths which are the preferred places for embrittlement (the old austenitic grain boundaries being decorated by carbides, these paths are much less frequent). It appears therefore that in this case, it is the fineness of the initial microstructure obtained by martensitic transformation and the high level of plastic deformation before rupture which has rendered the rupture surface difficult to interpret. This combination of sub-critical propagation and an intense plastic deformation completely modifies the appearance of the rupture surface [MAR 12].

In the case of $304 \mathrm{~L} / \mathrm{Na}$, a high martensitic transformation rate $\left(\gamma / \alpha^{6}\right)$ can also be seen which is the principal mechanism for the formation of interfaces at a submicronic scale. These are the interfaces formed by twinning during plastic deformation undergoing LME. It emerges from these small-scale investigations that for industrial materials such as T91 martensitic steels or austenitic 304L, interfacial rupture under the influence of liquid metal is the principal propagation mechanism for the crack. The influence of intragranular cleavage is less although these cracking paths are not excluded in principle. In the case of fatigue loading, the analysis of the microstructural paths shows a significant part of interfacial rupture and also the intragranular routes which could involve the dislocation structures formed by fatigue [GON 16b].

a)

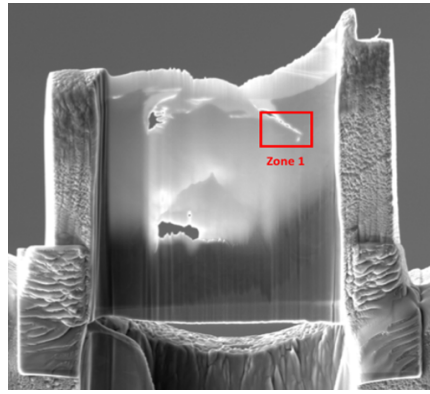

b)

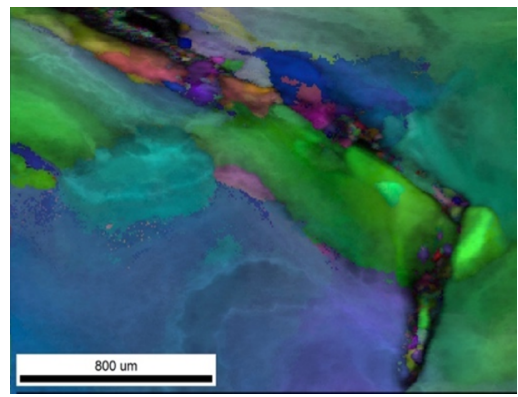

Figure 22.16. a) SEM view (secondary electrons) of an FIB lamella taken under the rupture surface of $304 \mathrm{~L}$ tested in sodium; b) orientation map zone 1 . The stopped crack is visible in black [BAR 17]. For a color version of this figure, see www.iste.co.uk/blanc/coupling.zip

Thus it appears that a large part of LME phenomenology is related to an interfacial rupture problem. In particular it is necessary to take into account the microstructure's evolution during plastic deformation to explain the cracking. One can note the insufficiency of single fractography to correctly interpret the environmental rupture surfaces for LME in view of the high level of plastic deformation before rupture in many cases. These characteristics require adopting 
small-scale study methodologies to correctly characterize the rupture modes looking at both the rupture surface and the microstructural characteristics situated below. It is therefore obvious nevertheless that studying the model systems allows us to learn a lot in order to understand LME for systems with industrial interests [WOL 02]. The basic phenomenon, rupture at interfaces, must be similar in the vast majority of systems but it is modulated by the microstructural complexity of the materials present in these applications.

\subsubsection{Mechanisms}

\subsubsection{Adsorption and surface energy}

The adsorption of an atom on a surface generally leads either to the formation of a physi-sorption type bond (van der Waals interactions characterized by low adsorption energies $<0.3 \mathrm{eV} /$ atom) or chemical-sorption with the interaction being iono-covalent or metallic (higher adsorption energies). The delocalized character of the metallic bond agrees very little with the adsorption of an isolated atom and is more adequate when we speak of adsorption of one or several mono-layers [SCH 01]. The most important adsorption effect here is to decrease the surface energy. We can illustrate this tendency in the case of the $\mathrm{Cu} / \mathrm{Hg}$ system on a (100) surface orientation where we calculate the adsorption energy according to the coverage rate for an $\mathrm{Hg}$ atom deposited on the surface [COL 14].

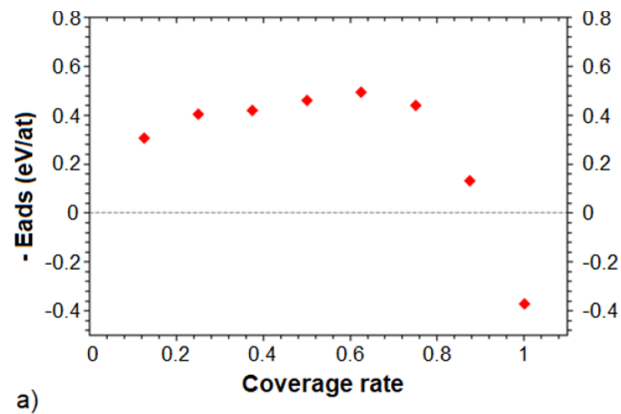

a)

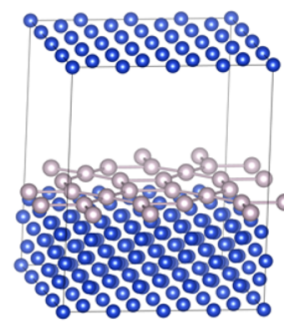

b)

Figure 22.17. a) $E_{a d s}$ according to the coverage rate; b) cell showing an arranged surface(100) and the adsorption of a single layer [COL 14]. For a color version of this figure, see www.iste.co.uk/blanc/coupling.zip

The energy landscape seen by an adsorbate (surface potential) can be described as a periodic function with a periodicity in the order of cell size (depending on the orientation). The adsorption site on the surface can range from the peak position summit to the trough in this potential. The change of sign for the maximum rate 
reflects the steric repulsion between adsorbates, the fact that the atom absorbed then interacted repulsively with its neighbors. This surface energy, typically a solid-vapor interface, is then a function of the coverage rate $\left(\Theta=\frac{\Gamma}{\Gamma_{t}}\right.$, is the ratio of the number of occupied sites to the number of sites available) and the adsorption energy:

$$
\gamma_{S V}(\Theta)=\gamma_{0}-\frac{\Theta \cdot\left|E_{a d s}\right|}{a^{2}}\left(\mathrm{~J} / \mathrm{m}^{2}\right) \text { where } \mathrm{a}^{2} \text { is the fundamental adsorption surface }
$$

We thus obtain that it depends linearly on the coverage rate in first approximation. It is this decreasing tendency which is used as a basis for adsorptionbased LME mechanisms. Beyond a maximum rate representing a monolayer, the interface becomes more complex because it includes the adsorption effect of a second layer and beyond until liquid.

\subsubsection{Atomic scale mechanisms}

Several atomic scale mechanisms are proposed to explain LME [FER 97b].

The first effect which can be used as an explanatory framework is based on the reduction of the cohesion by the adsorption of the liquid metal at the bottom of the crack (Rehbinder effect [REH 72]). The decrease in surface energy induced by adsorption can be connected to the decrease in cohesive energy, the energy required to separate two surfaces. Griffith's fragile rupture theory connects the surface energy $\gamma_{\mathrm{SL}}$ to the critical cleavage stress $\sigma_{\mathrm{c}}$ [GRI 21]. The decrease of the surface energy induced by the adsorption leads to a decrease in the critical debonding stress for elastic loading of a crack length a (E is Young's modulus):

$$
\sigma_{c}=\sqrt{\frac{2 E \gamma_{S L}}{\pi a}}
$$

This mechanism implies that the embrittlement effect is located at the surface and results only from the adsorption by the liquid metal. The direct relationship between the surface energy $\gamma_{\mathrm{SL}}$ and the critical rupture stress has been observed in the intergranular rupture of aluminum in contact with lead, bismuth or cadmium (in the form of fine immiscible inclusions segregated at the grain boundaries) [ROT 80]. This model allows us also to explain the dependence observed between the grain size or the deformation rate and the fragile/ductile transition temperature.

The second mechanism which competes with the first is the emission of dislocations induced by adsorption at the crack tip [LYN 84]. This emission is induced by lowering the critical shear stress under the action of adsorption. This results in an extremely localized micro-plastic deformation and the crack then propagates by rupture in the shear bands facilitated by adsorption. The intensity of 
this plastic localization is such that accelerated cavitation is expected to develop upstream of the crack tip to give a rupture surface with a morphology of small ductile cavities which are joined by the crack tip. This mechanism is coherent with the influence of surface energy on the dislocation emission process that adds up to the Peierls friction stress, like an energy barrier [AND 17, SCH 03]. The lowering of the surface energy (which from a mechanical viewpoint leads to the lowering of the energy cost for the creation of the sliding step) allows us to decrease the emission energy barrier for a dislocation. This mechanism, which is purely based on surface observations using electronic microscopy and which postulates about the immediate adsorption effect, is nevertheless difficult to reconcile with the observations of delayed ruptures in certain systems.

The third type of mechanism is based on the solubility of an element of the material in the liquid metal which allows us to have a dissolution which is not in equilibrium for the crack tip following precipitation of the element dissolved outside of the loaded zone. The supersaturated atoms diffuse and redeposit on the wall of the crack in a zone which is subjected to less stress. Robertson's model takes as a driving force the dissolution at the crack tip accelerated by the mechanical stress [ROB 66]. The driving force is modulated by the plastic zone at the bottom of the crack and by the roughness in later developments by Glickman [GLI 07]. The great merit of this type of mechanism is that it allows us to estimate a maximum cracking rate that can potentially be compared to experience:

$$
v_{\text {crack }}=\frac{C_{0} D \Omega^{2}}{k_{B} T \rho}\left(\frac{\sigma^{2}}{2 E}-\frac{\gamma_{S L}}{\rho}\right)
$$

This type of model is falsifiable because it is the only one which makes a prediction for the evolution of the speed with the temperature for example. In this respect, it is challenged by several experiments which have shown opposite trends for the activation energy by increasing the temperature [HAD 09]. The experimental results promote an interpretation of a return to ductility controlled by desorption. No mechanism is currently proven in LME.

\subsection{References}

[AND 17] ANDRIC P., CURTIN W., "New theory for Mode I crack-tip dislocation emission", Journal of the Mechanics and Physics of Solids, vol. 106, pp. 315-337, 2017.

[AUG 04] AUGER T., LORANG G., GUÉRIN S. et al., "Effect of contact conditions on embrittlement of T91 steel by lead-bismuth", Journal of Nuclear Materials, vol. 335, pp. 227-231, 2004. 
[AUG 08] AUger T., Serre I., LORANG G. et al., "Role of oxidation on LME of T91 steel studied by Small Punch Test", Journal of Nuclear Materials, vol. 376, pp. 336-340, 2008.

[AUG 11] Auger T., Gorse D, Hamouche-Hadjem Z. et al., "Fracture mechanics behavior of the T91 Martensitic steel in contact with liquid lead-bismuth eutectic for application in an Accelerator Driven System", Journal of Nuclear Materials, vol. 415, pp. 293-301, 2011.

[BAK 14] BAKER B.W., BREWER L.N., "Evaluation of liquid metal embrittlement susceptibility of oxide dispersion strengthened steel MA956", Journal of Nuclear Materials, vol. 453, pp. 239-246, 2014.

[BAL 13] Balbaud-Celerier F., Martinelli L., Phénomènes de corrosion dans les métaux liquides, Techniques de l'ingénieur, ref. no. cor640, 2013.

[BAR 17] BARKia B., Auger T., Courouau J.L. et al., "Multiscale investigation of crack path and microstructural changes during liquid metal embrittlement of 304L austenitic steel in liquid sodium", Corrosion Science, vol. 127, pp. 213-221, 2017.

[BAR 18] Barkia B., Auger T., Courouau J.L. et al., "Wetting by liquid sodium and fracture path analysis of sodium induced embrittlement of 304L stainless steel", Journal of Material Research, vol. 33, no. 2, pp. 121-129, 2018.

[BOS 07] Bosch R.W., VAN DyCK S., Almazouzi A., "Investigation of the susceptibility of EUROFER97 in lead-lithium to liquid metal embrittlement (LME)", Fusion Engineering Design, vol. 82, no. 15, pp. 2615-2620, 2007.

[CAR 17] CARLE C., Oligocyclic fatigue de l'acier martensitique T91 en présence de l'eutectique $\mathrm{Pb}$-Bi liquide et influence de l'oxygène, $\mathrm{PhD}$ thesis, Université de Lille, 2017.

[COA 06] COADE R., COLDHAM D., "The interaction of mercury and aluminum in heat exchangers in a natural gas plants", International Journal of Pressure Vessels and Piping, vol. 83, pp. 336-342, 2006.

[COE 10] Coen G., Van Den Bosch J., Almazouzi A. et al., "Investigation of the effect of lead-bismuth eutectic on the fracture properties of T91 and 316L", Journal of Nuclear Materials, vol. 385, pp. 122-128, 2010.

[COL 14] COLOMBAU J., Embrittlement du cuivre par le mercure liquide : étude expérimentale et numérique, $\mathrm{PhD}$ thesis, CentraleSupélec, 2014.

[COU 04] COUROUAU J.-L., "Electrochemical oxygen sensors for on-line monitoring in lead-bismuth alloys: Status of development", Journal of Nuclear Materials, vol. 335, pp. 254-259, 2004.

[DAI 06] DAI Y, LONG B., GROESCHEL F., "Slow strain rate tensile tests on T91 in static lead-bismuth eutectic", Journal of Nuclear Materials, vol. 356, pp. 222-228, 2006. 
[ERS 16] ERSOY F., GaVRILOV S., VerbeKen K., "Investigating liquid-metal embrittlement of T91 steel by fracture toughness tests", Journal of Nuclear Materials, vol. 472, pp. 171-177, 2016.

[EUS 99] Eustathopoulos N., Nicholas M.G., Drevet B. (eds), Wettability at High Temperatures, vol. 3, Pergamon, 1999.

[FER 96] FERNANDES P.J.L., JONES D.R.H., "Specificity in liquid metal induced embrittlement", Engineering Failure Analysis, vol. 3, no. 4, pp. 299-302, 1996.

[FER 97a] FERNANDES P.J.L., JONES D.R.H., "The effects of microstructure on crack initiation in liquid-metal embrittlement", Engineering Failure Analysis, vol. 4, pp. 195-204, 1997.

[FER 97b] FeRnANDES P.J.L., JONES D.R.H., "Mechanisms of liquid metal induced embrittlement", International Materials Reviews, vol. 42, pp. 251-261, 1997.

[GLI 07] GLICKMAN E., "On the role of stress, strain and diffusion in dissolution condensation mechanism of liquid metal embrittlement", Defect and Diffusion Forum, vol. 264, pp. 141-149, 2007.

[GON 14] GONG X., MARMY P., QIN L. et al., "Effect of liquid metal embrittlement on low cycle fatigue properties and fatigue crack propagation behaviour of a modified 9Cr-1Mo ferritic-martensitic steel in an oxygen-controlled leadbismuth eutectic environment at $350^{\circ} \mathrm{C}$ ", Materials Science \& Engineering A, vol. 618, pp. 406-415, 2014.

[GON 16a] GONG X., MARMY P., QIN L. et al., "Temperature dependence of liquid metal embrittlement susceptibility of a modified 9Cr1Mo steel under low cycle fatigue in lead-bismuth eutectic at $160-450^{\circ} \mathrm{C}$ ", Journal of Nuclear Materials, vol. 468, pp. 289-298, 2016.

[GON 16b] GONG X., MARMY P., VOLODIN A. et al., "Multiscale investigation of quasi-brittle fracture characteristics in a $9 \mathrm{Cr}-1 \mathrm{Mo}$ ferritic-martensitic steel embrittled by liquid lead-bismuth under low cycle fatigue", Corrosion Science, vol. 102, pp. 137-152, 2016.

[GRI 21] GRIFFITH A.A., "The phenomena of rupture and flow in solids", Phil. Trans. R. Soc. Lond. A, vol. 221, pp. 163-198, 1921.

[HAA 01] DE HAAS M.-J., Grain boundary phenomena and failure of aluminium alloys, PhD thesis, University of Gröningen, 2001.

[HAD 09] Hadjem-Hamouche Z., Auger T., Guillot I., "Temperature effect in the maximum propagation rate of a liquid metal filled crack: The T91 martensitic steel/Lead-Bismuth Eutectic system", Corrosion Science, vol. 51, pp. 2580-2587, 2009.

[HAM 11a] HAMDANE O., Etude des mécanismes de plasticité et d'endommagement de l'acier martensitique T91 en présence de sodium liquide, $\mathrm{PhD}$ thesis, Université de Lille, 2011. 
[HAM 11b] Hamdane O., Bouquerel J., Proriol Serre I. et al., "Effect of heat treatment on liquid sodium embrittlement of T91 martensitic steel", Journal of Materials Processing Technology, vol. 211, no. 12, pp. 2085-2090, 2011.

[HAM 14] Hamdane O., Proriol-Serre I., Vogt J.B. et al., "ToF-SIMS analyses of brittle crack initiation of T91 steel by liquid sodium", Materials Chemistry and Physics, vol. 145, pp. 243-249, 2014.

[HEM 13] Hemery S., Auger T., Courouau J.-L. et al., "Effect of oxygen on liquid sodium embrittlement of T91 martensitic steel", Corrosion Science, vol. 76, pp. 441-452, 2013.

[HOJ 11] HojnA A., Di GABRIELE F., "On the kinetics of LME for the ferritic martensitic steel T91 immersed in liquid Pb-Bi eutectic", Journal of Nuclear Materials, vol. 413, no. 1, pp. 21-29, 2011.

[KAN 09] KANNAN R., SANDhya R., GANESAN V. et al., "Effect of sodium environment on low cycle fatigue properties of modified $9 \mathrm{Cr}-1 \mathrm{Mo}$ ferritic martensitic steel”, Journal of Nuclear Materials, vol. 384, pp. 286-291, 2009.

[KIN 05] KINSTLER T.J., "Current knowledge of the cracking of steels during galvanizing - a synthesis of the available technical literature and collective experience for the American Institute of Steel Construction", Engineering, vol. 5, no. 8, 2005.

[KON 06] KONDO M., TAKAHASHI M., "Metallurgical analysis of a tube ruptured in the lead bismuth corrosion test facility", Journal of Nuclear Science and Technology, vol. 43, no. 2, pp. 174-178, 2006.

[LEG 00] LEGRIS A., NiCAISE G., VoGT J.-B. et al., "Embrittlement of a martensitic steel by liquid lead”, Scripta mater., vol. 43, pp. 997-1001, 2000.

[LON 08a] LONG B., TONG Z., Groeschel F. et al., "Liquid Pb-Bi embrittlement effects on the T91 steel after heat treatments", Journal of Nuclear Materials, vol. 377, pp. 219-224, 2008.

[LON 08b] LONG B., DAI Y., "Investigation of LBE embrittlement effects on the fracture properties of T91", Journal of Nuclear Materials, vol. 376, pp. 341-345, 2008 .

[LUD 05] Ludwig W., Pereiro-Lopez E., Bellet D., "In situ investigation of liquid Ga penetration in Al bicrystal grain boundaries: Grain boundary wetting or liquid metal embrittlement?", Acta Materialia, vol. 53, pp. 151-162, 2005.

[LYN 84] LYNCH S.P., "Metal induced embrittlement of ductile materials and dislocation emission from crack tips", Scripta Metallurgica, vol. 18, pp. 509-513, 1984.

[MAR 12] MARTin M., Auger T., JOHnson D.D. et al., "Liquid-metal-induced fracture mode of martensitic T91 steels", Journal of Nuclear Materials, vol. 426, pp. 71-77, 2012. 
[MRA 09] MRAZ L., LeSAY J., "Problems with reliability and safety of hot dip galvanized steel structures", Soldagem Insp. São Paulo, vol. 14, no. 2, pp. 184-190, 2009.

[MUL 60] Mullins W.W., "Grain boundary grooving by volume diffusion", Transactions of the Metallurgical Society of AIME, vol. 218, pp. 354-361, 1960.

[NEA 15] NEA, OECD, Handbook on lead-bismuth eutectic alloy and lead properties, materials compatibility, thermal-hydraulics and technologies, no. $7268,2015$.

[NIC 01] NICAISE G., Sensibilité de l'acier martensitique Z10CDNbV9-1 à la embrittlement par les métaux liquides, PhD thesis, Université de Lille, 2001.

[OKA 13] OKAFOR I.C., O’MAlley R.J., PrayaKaraO K.R. et al., "Effect of zinc galvanization on the microstructure and fracture behavior of low and medium carbon structural steels", Engineering, vol. 5, pp. 656-666, 2013.

[RAU 08] RAUCH E.F., VÉRON M., PORTILlo J. et al., "Automatic crystal orientation and phase mapping in TEM by precession diffraction", Microsc. Anal., vol. 22, pp. S5-S8, 2008.

[REH 72] REHBINDER P.A., SHCHUKIN E.D., "Surface phenomena in solids during deformation and fracture processes", Progress in Surface Science, vol. 3, pp. 97-188, 1972.

[ROB 66] RoBERTSON W.M., "Propagation of a crack filled with liquid metal", Trans. Met. Soc. AIME, vol. 236, pp. 1478-1482, 1966.

[ROT 80] Roth M.C., Weatherly G.C., Miller W.A., "The temperature dependence of the mechanical properties of aluminum alloys containing lowmelting-point inclusions", Acta Metallurgica, vol. 28, pp. 841-853, 1980.

[SCH 01] SCHEFFLER M., STAMPFL C., "Theory of adsorption on metal substrates", in Horn K., Scheffler M. (eds), Handbook of Surface Science, vol. 2, North Holland, Amsterdam, 2001.

[SCH 03] SCHOECK G., "The emission of dislocations from crack tips: A critical assessment”, Materials Science \& Engineering A, vol. 356, pp. 93-101, 2003.

[SKE 94] Skeldon P., Hilditch J.P., HuRley J.R. et al., "The liquid metal embrittlement of $9 \mathrm{Cr}$ steel in sodium environment and the role of non metallic impurities", Corrosion Science, vol. 36, pp. 593-610, 1994.

[THO 94] ThOMAS J.K., Lyer N.C., PEACOCK H.B. et al., "Evaluation of liquid metal embrittlement of stainless steel 304 by cadmium-aluminum solutions", Journal of Nuclear Materials, vol. 210, pp. 216-225, 1994.

[VAN 09] Van Den Bosch J., Coen G., Almazouzi A. et al., "Fracture toughness assessment of ferritic-martensitic steel in liquid lead-bismuth eutectic", Journal of Nuclear Materials, vol. 385, pp. 250-257, 2009. 
[VER 05] VERLEENE A., Comportement in fatigue de l'acier martensitique T91 à $300^{\circ} \mathrm{C}$ dans l'eutectique plomb-bismuth liquide, $\mathrm{PhD}$ thesis, Université de Lille, 2005.

[VOG 13] Vogt J.-B., Proriol Serre I., "Fatigue behavior of a martensitic and an austenitic steel in heavy liquid metals", Procedia Engineering, vol. 55, pp. 812-818, 2013.

[VOG 17] Vogt J.-B., Ye C., CARle C. et al., "Monotonic and cyclic mechanical behaviour of T91 in lead-bismuth eutectic: Is T91 reliable enough material for ADS?", Proc. Workshop Technology and Components of Accelerator-Driven Systems, pp. 201-209, 2017.

[WES 79] WeSTWOOD A.R.C., LATANISION R.M., "Adsorption-induced liquid metal embrittlements", in DRALEY J.E., WeEKS J.R. (eds), Corrosion by Liquid Metals: Proceedings of the 1969 Fall Meeting of the Metallurgical Society of AIME, Plenum Press, Philadelphia, 1979.

[WOL 02] WOLSKi K., RENAUdOT N., HARABASZ A. et al., "The use of ultra-highpurity metals and alloys to study environment-sensitive damage mechanisms in nuclear power plants", Phys. Stat. Sol. (a), vol. 189, pp. 59-68, 2002.

[YE 14a] YE C., Liquid metal embrittlement of the T91 steel in lead bismuth eutectic, PhD thesis, Université de Lille, 2014.

[YE 14b] Ye C., Vogt J.-B., Proriol Serre I., "The role of loading rate and of the oxygen content in the liquid metal", Materials Science \& Engineering A, vol. 608 , pp. $242-248,2014$.

[YUR 11] YuREChKo M., Schroer C., Wedemeyer O. et al., "Creep-to-rupture of $9 \% \mathrm{Cr}$ steel T91 in air and oxygen-controlled lead at $650^{\circ} \mathrm{C}$ ", Journal of Nuclear Materials, vol. 419, pp. 320-328, 2011.

[ZHA 10] Zhang J., HoSeman P., Maloy S., "Models of liquid metal corrosion", Journal of Nuclear Materials, vol. 404, pp. 82-96, 2010. 